\title{
Estimating Regional Soil Moisture Distribution Based on NDVI and Land Surface Temperature Time Series Data in the Upstream of the Heihe River Watershed, Northwest China
}

\author{
Xiao Bai ${ }^{1}$, Lanhui Zhang ${ }^{1,+}\left(\mathbb{D}\right.$, Chansheng $\mathrm{He}^{1,2, *,+\mathbb{D}}$ and Yi Zhu ${ }^{1}$ \\ 1 Key Laboratory of West China's Environmental System (Ministry of Education), Center for Dryland Water \\ Resources Research and Watershed Science, College of Earth and Environmental Sciences, Lanzhou \\ University, Lanzhou 730000, China; ibaixiao@hotmail.com (X.B.); lhzhang@lzu.edu.cn (L.Z.); \\ zhuy15@lzu.edu.cn (Y.Z.) \\ 2 Department of Geography, Western Michigan University, Kalamazoo, MI 49008, USA \\ * Correspondence: he@wmich.edu \\ + These authors contributed equally to this work.
}

Received: 10 June 2020; Accepted: 24 July 2020; Published: 28 July 2020

\begin{abstract}
Temporal and spatial variability of soil moisture has an important impact on hydrological processes in mountainous areas. Understanding such variability requires soil moisture datasets at multiple temporal and spatial scales. Remote sensing is a very effective method to obtain surface $(\sim 5 \mathrm{~cm}$ depth) soil moisture at the regional scale but cannot directly measure soil moisture at deep soil layers ( $>5 \mathrm{~cm}$ depth) currently. This study chose the upstream of the Heihe River Watershed in the Qilian Mountain Ranges in Northwest China as the study area to estimate the profile soil moisture (0-70 cm depth) at the regional scale using satellite Vegetation Index (NDVI) and Land Surface Temperature (LST) products. The study area was divided into 31 zones according to the combination of altitude, vegetation and soil type. Long-term in situ soil moisture observation stations were set up at each of the zones. Soil moisture probe, $\mathrm{ECH} 2 \mathrm{O}$, was used to collect soil moisture at five layers $(0-10,10-20,20-30,30-50$ and $50-70 \mathrm{~cm})$ continuously. Multiple linear regression equations of time series MODIS (Moderate-resolution Imaging Spectroradiometer) NDVI, LST and soil moisture were developed for each of the five soil layers at the 31 zones to estimate the soil moisture $(0-70 \mathrm{~cm})$ on a regional scale with a spatial resolution of $1 \mathrm{~km}^{2}$ and a temporal resolution of 16-d from October, 2013 to September, 2016. The correlation coefficient $R$ of the regression equations was between 0.47 and 0.94 , the RMSE was 0.03 , indicating that the estimation method based on the MODIS NDVI and LST data was suitable and could be applied to alpine mountainous areas with complex topography, soil and vegetation types. The overall pattern of soil moisture spatial distribution indicated that soil moisture was higher in the eastern region than in the western region, and the soil moisture content in the whole study area was $14.5 \%$. The algorithm and results provide novel applications of remote sensing to support soil moisture data acquisition and hydrological research in mountainous areas.
\end{abstract}

Keywords: soil moisture estimation; in situ observations; MODIS NDVI and LST; soil moisture variability; the Heihe River watershed

\section{Introduction}

Soil moisture is an essential component of the terrestrial water cycle, and serves as a critical link between the precipitation, surface water, groundwater and vegetation water [1-6]. It plays an important role in hydrological processes and land surface-atmosphere interactions 
such as the Soil-Plant-Atmosphere Continuum (SPAC) [7]. Mountains are water towers of rivers, and understanding the distribution of soil moisture over the mountainous areas, is essential for hydrological modeling and water resources management, especially in arid areas, such as Northwest China [8]. Since its strong temporal and spatial variability, soil moisture has an important effect on the distribution of regional water resources, and ecosystem services [9-11]. Unfortunately, the impact of soil moisture on both hydrological processes and ecosystem services over the regional scale has been poorly understood due to the lack of long-term, large-scale soil moisture datasets, particularly in such mountainous areas [12].

Over the past decades, acquisition of soil moisture data has evolved from traditional gravimetric methods to the applications of semi-automatic and automatic monitoring of the neutron probe, time-domain reflectometry (TDR), frequency domain reflectometry (FDR). At the regional scale, remote sensing, particularly satellites, provides soil moisture estimates over large areas [13], which is mainly based on the measurement of electromagnetic radiation energy reflected or emitted from the land surface. Satellite soil moisture products mainly include AMSR (Advanced Microwave Scanning Radiometer) [14], ERS (European Remote Sensing Satellite) [15], ASCAT (The Advanced Scatterometer) [16,17], SMOS (Soil Moisture and Ocean Salinity) [18] and SMAP (Soil Moisture Active Passive) [19]. In addition, soil moisture data at the regional scale can also be obtained through model simulation and data assimilation [20]. Common weaknesses of these soil moisture products are that the accuracy and resolution in heterogeneous mountainous areas are still too coarse to meet the study requirements [21,22]. Temperature Vegetation Dryness Index (TVDI) [23] and Apparent Thermal Inertia (ATI) $[24,25]$ are two common methods to estimate soil moisture by using visible light and near-infrared wavebands. However, both the TVDI and ATI methods mainly establish the correlation between the measured soil moisture on the ground and the TVDI or ATI indices to estimate the soil moisture distribution in the region. For alpine and heterogeneous areas, the complexity of the underlying surface leads to a series of uncertainties, such as the inconsistent linear relationship between soil moisture and ATI, resulting in large estimation errors. In addition to these deficiencies, current remote sensing methods mainly concentrate on the relationship between the surface reflection value and the in situ observations to estimate the surface soil moisture at the regional scale [23]. Few studies have estimated the profile soil moisture, particularly in the alpine areas. Li et al. [26] used remotely sensed surface soil moisture to calculate deep soil moisture by a flux model, and pointed out that remote sensing surface soil moisture in wet areas was suitable for estimating profile soil moisture, while the results in dry areas had large errors. Tobin et al. [27] downscaled AMSR-E and ERS-CCI (European remote sensing satellite-climate change initiative) soil moisture data using an exponential filter (ExpF) with soil moisture index derived from MODIS NDVI. Tian et al. [3] coupled the surface soil moisture and profile soil moisture, applied ExpF, artificial neural networks (ANN) and cumulative distribution function matching (CDF) methods in an alpine region to estimate the deep profile soil moisture at the regional scale. Lu et al. [28] investigated a nonlinear autoregressive neural network method with exogenous input (NARXnn) to estimate time series soil moisture by multiple remote sensing data. Estimation of 0-100 cm soil moisture by the principle of maximum entropy achieved better results than those obtained by the exponential decaying function in the Southeastern USA, a subtropical humid area [29]. With the measurement of the spectral characteristics of soil profile, Balet et al. [30] inferred soil moisture conditions based on the MARMIT (MultilAyer Radiative Transfer Model for soIl reflecTance) model. Over the past decades, MODIS LST and NDVI products have been widely used in agriculture, ecosystem and global change research [31,32]. The NDVI is an index that shows the difference between vegetation reflectance in the visible and near-infrared bands and the soil background [33]. Land Surface Temperature (LST) is a key parameter for agricultural drought monitoring, hydrological research and urban thermal environment [34,35]. Both MODIS LST and NDVI data are widely used for soil moisture estimation based on the TVDI and ATI methods (e.g., [21,36]). For example, Yang et al. [37] proposed a trapezoidal space defined by remote sensed vegetation cover and LST to estimate surface soil moisture. Compared with the aforementioned soil moisture products, both MODIS LST and NDVI have higher 
spatial resolutions in soil moisture monitoring. In addition, both MODIS LST and NDVI are usually used for downscaling the satellite soil moisture products [22,38].

In recent years, many scale transformation studies for soil moisture retrieval have been done. However, the accuracy of most of these works was poor in mountainous areas, and the temporal and spatial resolutions of profile soil moisture estimation were still too coarse to meet the needs of hydrological research in heterogeneous mountain areas. To improve the deficiency in estimating profile soil moisture distribution over mountainous areas, this study proposed a novel approach to estimate profile soil moisture by integrating remote sensing LST and NDVI products and in situ soil moisture observations. The upstream of the Heihe River Watershed in the Qilian Mountain Ranges in Northwest China was chosen as the study area to estimate the profile soil moisture $(0-70 \mathrm{~cm}$ depth $)$ at the regional scale by remote sensing. The study area was divided into 31 zones based on the combination of altitude, vegetation and soil type. In situ soil moisture observation stations were set up at each of the zones to collect soil moisture at five layers $(0-10,10-20,20-30,30-50$ and 50-70 cm) continuously for the period of October, 2013 to September, 2016. Multiple time series MODIS NDVI, LST and soil moisture were fitted for each of the five soil layers at the 31 zones to estimate the profile soil moisture distribution on a regional scale. The study aims to provide a novel approach to estimate profile soil moisture distribution by remote sensing to support hydrological research in mountainous areas.

\section{Study Area}

The in situ soil moisture data for this study were obtained from the Soil Hydrological Heterogeneity Observation Network in the upstream of the Heihe River Watershed $\left(97^{\circ} 46^{\prime}-101^{\circ} 11^{\prime} \mathrm{E}, 38^{\circ} 12^{\prime}-39^{\circ} 22^{\prime} \mathrm{N}\right)$ Northwest, China (Figure 1a), a $2.75 \times 104 \mathrm{~km}^{2}$ study area with 30 tributaries, elevation ranging from $2000 \mathrm{~m}$ to $5580 \mathrm{~m}$ (above sea level, a.s.l) on the northeast edge of the Qinghai-Tibet Plateau. The spatial distribution of annual mean temperature ranges from $-3.1{ }^{\circ} \mathrm{C}$ to $3.6^{\circ} \mathrm{C}$, and annual precipitation ranges from $200 \mathrm{~mm}$ to $700 \mathrm{~mm}$ [39]. Perennial snow cover and glaciers are present above $4000 \mathrm{~m}$ with permafrost extending down to $3700 \mathrm{~m}$. Affected by mountain climate and terrain, there is a remarkable vertical zonal distribution of vegetation and soils in the study area. In the upstream of the Heihe River Watershed, the major vegetation types include coniferous forest (Picea crassifolia), shrub (Potentilla fruticosa), steppe (Stipa purpurea Griseb), alpine meadow (Kobresia pygmaea Clarke), alpine sparse vegetation (Saussurea medusa Maxim) and desert (Sympegma regelii Bunge) [22]. The main soil types include aeolian sandy soil, cold desert soil, alpine meadow soil and mountain swamp chestnut soil [8]. 


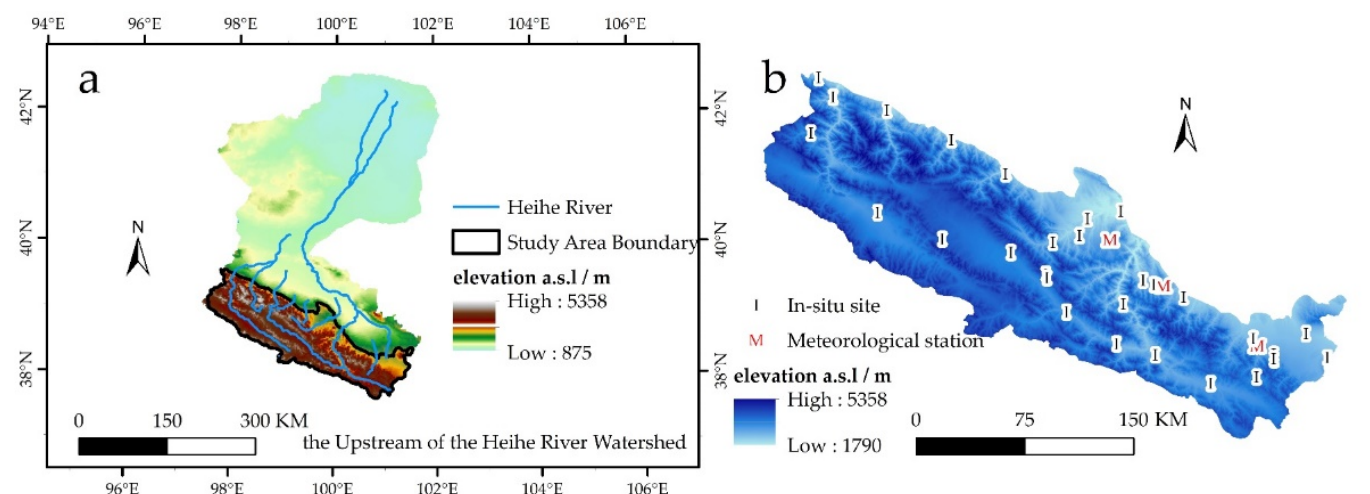

C

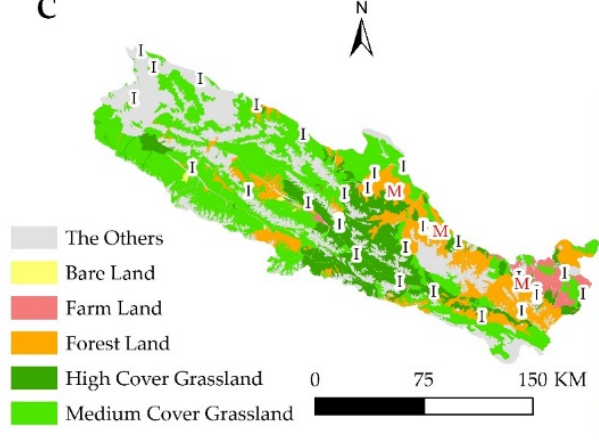

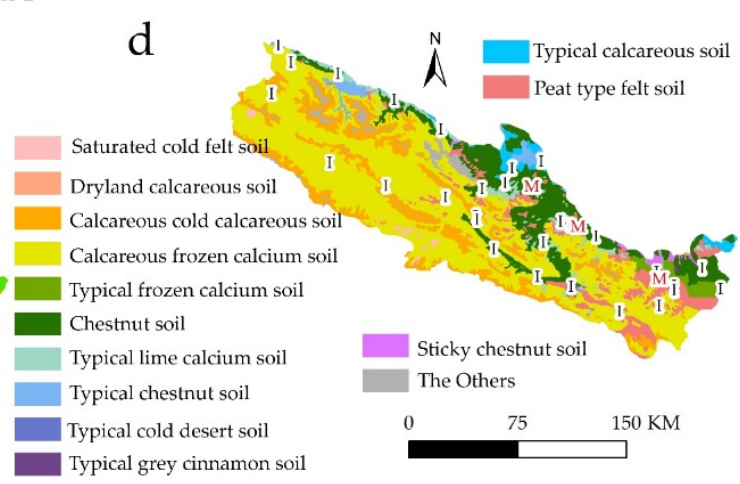

Figure 1. The in situ observation stations in the upstream of the Heihe River Watershed, Northwest China. The number shows 31 land use/land cover (LULC) soil elevation types (details in Table 1). (a) the study area in China; (b) the elevation of the study area, black circles represent the in situ sites and crimson circles represent the three automatic meteorological station sites; (c) land use types distribution in the study area; (d) soil types. The locations of in situ monitoring sites and meteorological stations are also indicated in (b), (c) and (d). 
Table 1. Soil and vegetation types at the in situ observation sites and automatic meteorological stations.

\begin{tabular}{|c|c|c|c|c|}
\hline ID & Elevation Range (m) & Soil Type & Vegetation Type & Percent (\%) of Area \\
\hline No.1 & $2000-2500$ & Typical lime calcium soil & Medium coverage grassland & 1.53 \\
\hline No. 2 & $2000-2500$ & Chestnut soil & Medium coverage grassland & 0.91 \\
\hline No.3 & $2000-2500$ & Sticky chestnut soil & Medium coverage grassland & 1.34 \\
\hline No.4 & $2500-3000$ & Typical chestnut soil & Medium coverage grassland & 3.06 \\
\hline No. 5 & $2500-3000$ & Chestnut soil & Medium coverage grassland & 2.87 \\
\hline No.6 & $3000-3500$ & Chestnut soil & Medium coverage grassland & 0.96 \\
\hline No.7 & $3000-3500$ & Calcareous frozen calcium soil & Medium coverage grassland & 2.48 \\
\hline No.8 & $3000-3500$ & Saturated cold felt soil & Medium coverage grassland & 3.79 \\
\hline No.9 & $3500-4000$ & Saturated cold felt soil & Medium coverage grassland & 7.57 \\
\hline No.10 & $3500-4000$ & Calcareous frozen calcium soil & Medium coverage grassland & 5.47 \\
\hline No.11 & $2500-3000$ & Typical chestnut soil & Forest land & 3.22 \\
\hline No.12 & $2500-3000$ & Typical gray cinnamon soil & Forest land & 1.34 \\
\hline No.13 & $2500-3000$ & Peat type felt soil & Forest land & 0.97 \\
\hline No.14 & $2500-3000$ & Chestnut soil & Forest land & 1.63 \\
\hline No.15 & $3000-3500$ & Peat type felt soil & Forest land & 2.77 \\
\hline No.16 & $3000-3500$ & Saturated cold felt soil & Forest land & 2.62 \\
\hline No.17 & $3500-4000$ & Peat type felt soil & Forest land & 1.02 \\
\hline No.18 & $2500-3000$ & Typical calcareous soil & Farm land & 2.05 \\
\hline No.19 & $2500-3000$ & Dryland calcareous soil & Farm land & 1.66 \\
\hline No.20 & $2500-3000$ & Calcareous cold calcareous soil & Bare land & 1.31 \\
\hline No.21 & $3000-3500$ & Calcareous cold calcareous soil & Bare land & 1.74 \\
\hline No.22 & $3000-3500$ & Saturated cold felt soil & Bare land & 1.04 \\
\hline No.23 & $3500-4000$ & Typical frozen calcium soil & Bare land & 1.48 \\
\hline No.24 & $4000-4500$ & Typical cold desert soil & Bare land & 9.33 \\
\hline No. 25 & $4000-4500$ & Saturated cold felt soil & Bare land & 3.54 \\
\hline No.26 & $2500-3000$ & Typical chestnut soil & High coverage grassland & 1.24 \\
\hline No.27 & $2500-3000$ & Chestnut soil & High coverage grassland & 1.01 \\
\hline No. 28 & $3000-3500$ & Typical chestnut soil & High coverage grassland & 2.40 \\
\hline No.29 & $3000-3500$ & Peat type felt soil & High coverage grassland & 1.54 \\
\hline No.30 & $3000-3500$ & Saturated cold felt soil & High coverage grassland & 3.73 \\
\hline No.31 & $3500-4000$ & Saturated cold felt soil & High coverage grassland & 7.02 \\
\hline Biandukou & $3000-3500$ & Peat type felt soil & High coverage grassland & \\
\hline Kangle & $2000-2500$ & Chestnut soil & Medium coverage grassland & \\
\hline Dayekou & $2500-3000$ & Chestnut soil & Forest land & \\
\hline
\end{tabular}

\section{Data Sets}

\subsection{In Situ Soil Moisture Monitoring Network}

\subsubsection{Soil Moisture Observation Network}

We established a Soil Hydrological Heterogeneity Observation Network comprising 31 stations (Figure 1) in the upstream of the Heihe River Watershed based on the combination of land use/land cover (LULC), soil type and elevation [39,40]. The distribution of soil and vegetation types is shown in Table 1. We used GPS (Garmin Oregon 550) to record latitude, longitude and altitude information for each station, the positional errors were within $\pm 1 \mathrm{~m}$ and altitude error was in $\pm 3-5 \mathrm{~m}$. We also recorded soil profile characteristics, vegetation status, root depth, aspect and slope using a geological compass, and took pictures of the sites every summer since June, 2014.

\subsubsection{Soil Moisture Measurement}

ECH2O 5TE soil moisture probes (DECAGON Devices, USA) and EM50 datalogger were installed at each in situ observation site. The 5TE probe measures the soil volumetric water content by the dielectric constant of the soil, with a precision of $\pm 3 \%$ and accuracy of $\pm 1-2 \%[3,41]$. The 5TE probes with a sensing depth of $2.5 \mathrm{~cm}$ were vertically centered in each of the sampled layers $(0-10 \mathrm{~cm}, 10-20 \mathrm{~cm}$, 20-30 cm, 30-50 cm and 50-70 cm) [42]. There is one probe in each layer for a total of five at each station. Datalogger EM50 was placed into a waterproof box sealed with high-strength glass glue and wrapped in a thick waterproof bag buried at a distance of at least $50 \mathrm{~cm}$ away from the 5 TE probes. The system collected soil moisture content data at $30 \mathrm{~min}$ intervals. Regular site maintenance took place twice a year at the beginning of June and at the end of October [3]. 
However, the mountainous study area is topographically complex and hard to reach, and it is a real challenge to maintain the soil moisture in situ observation network in the study area. Wireless data transmission is not possible because there is no mobile communication network coverage in the study area. As a result, there are some gaps in the measurement datasets due to severe weather and unstable batteries or sensors and the sensor damage by livestock and rats [3].

\subsection{Time Series Data of NDVI and LST}

NDVI was used as the vegetation index for the upscaling of the in situ soil moisture in this study. Specifically, we acquired the 16-day composite NDVI dataset MOD13A2 V6 (https://e4ft101. cr.usgs.gov/MOLT/MOD13A2.006/) of the sixth edition of terrestrial Level 3 standard data products for the period of October, 2013 to September, 2016, with a total of 69 scenes at a spatial resolution of $1 \mathrm{~km}^{2}$ [43]. We used the 8-d composite Land Surface Temperature (LST) data MOD11A2 V6 (https:/e4ft101.cr.usgs.gov/MOLT/MOD11A2.006/) for the same period of October, 2013 to September, 2016, for a total of 138 scenes with a resolution of $1 \mathrm{~km}^{2}$ [44]. Since the LST data were of 8-d composite, we used Maximum Value Composites (MVC) to process the LST dataset into a 16-d temporal resolution to match the temporal frequency of the NDVI dataset [45].

\section{Methodology}

The remote sensing vegetation index products contain a lot of noise caused by precipitation, cloud cover, human influence and the sensor itself in the data acquisition and process stages [46,47], and these factors can be collectively called random factors or residual parts.

The MOD13A2 V5 NDVI product was divided into the NDVI seasonal part and the NDVI residual part by using the Asymmetric Gaussian fitting method (AG) [48]. The multivariate linear regression fitting was used to establish multiple linear regression equations between the time series soil moisture data and the MODIS LST and NDVI. Subsequently, soil moisture upscaling equations were developed for every profile in the 31 vegetation-soil-elevation zones.

We installed only three automatic weather stations in the study region due to resource constraints. The limited number of precipitation observation stations cannot match the number of in situ soil moisture observations. Our in situ observations covered the three-year period (October, 2013 to September, 2016), and were able to represent the mean precipitation amount in the study region. Therefore, we only used MODIS LST and NDVI remote sensing data to estimate the spatial distribution of soil moisture in the study region.

\subsection{Asymmetric Gaussian Function Fitting}

Based on the noise information, NDVI data products can be divided into seasonal part, $\mathrm{NDVI}_{\mathrm{AG}}$, and residual part, $\mathrm{NDVI}_{\text {RES }}$ as shown in Equation (1). It needs to be reconstructed to remove the residual part [48].

$$
\mathrm{NDVI}=\mathrm{NDVI}_{\mathrm{AG}}+\mathrm{NDVI}_{\mathrm{RES}}
$$

The time series NDVI data curve reconstructed by the AG algorithm, can well express the interannual variation characteristics of the vegetation, and identify all the abnormal values [31]. The AG algorithm is a nonlinear least-squares fitting algorithm based on the Asymmetric Gaussian function. The original NDVI data and $\mathrm{NDVI}_{\mathrm{AG}}$ were used to obtain the residual part of the time series Vegetation Index (NDVI $\mathrm{RES}_{\mathrm{S}}$ ). The shallow soil moisture was greatly affected by the residual part which was likely to be related to short-term weather. The deep soil moisture was mainly subject to the seasonal changes in weather conditions and plant growth and environmental factors. 


\subsection{Multiple Linear Regression Fittings}

In this study, a multiple linear regression method was used to estimate the soil moisture using the in situ soil moisture observations, Vegetation Index (NDVI) and Land Surface Temperature (LST) data. The specific equation is as follows:

$$
\mathrm{SMC}=\mathrm{a}_{0}+\mathrm{a}_{1} * \mathrm{LST}+\mathrm{a}_{2} * \mathrm{NDVI}_{\mathrm{RES}}+\mathrm{a}_{3} * \mathrm{NDVI}_{\mathrm{AG}}
$$

In Equation (2), SMC is soil volumetric water content $\left(\mathrm{m}^{3} \mathrm{~m}^{-3}\right)$, LST is the Land Surface Temperature (K), $\mathrm{NDVI}_{\mathrm{RES}}$ and $\mathrm{NDVI}_{\mathrm{AG}}$ are the residual part and seasonal part of the vegetation index, respectively, $\mathrm{a}_{0}, \mathrm{a}_{1}, \mathrm{a}_{2}$ and $\mathrm{a}_{3}$ are the coefficients to be determined, $\mathrm{a}_{1}$ is in $\mathrm{m}^{3} \mathrm{~m}^{-3} \mathrm{~K}^{-1}$, while $\mathrm{a}_{2}$ and $\mathrm{a}_{3}$ are dimensionless.

Following Zhang et al. [22], the regression equations were evaluated by complex correlation coefficient (R), the F-test value, the confidence level $P$ and the root mean square error (RMSE). R describes the linear correlation of the dependent variable (soil moisture) and multiple explanatory variables in multivariate linear regression. The F-test was used to test whether the established regression equation is statistically significant. The larger the F-value, the better the fitted regression equation. Confidence level P indicated the significance level of the regression equation. The smaller the $p$-value, the more significant the equation. RMSE was used to measure the deviation between the predicted value and the true value. The smaller the RMSE value, the closer the simulated value to the observed value, the higher the accuracy of the regression equation. R and RMSE calculation formulas are as follows:

$$
\begin{gathered}
\mathrm{R}=\frac{\sum_{\mathrm{i}=1}^{\mathrm{n}}\left(\mathrm{SMC}_{\mathrm{obs}, \mathrm{i}}-\overline{\mathrm{SMC}_{\mathrm{obs}}}\right)\left(\mathrm{SMC}_{\mathrm{mod}, \mathrm{i}}-\overline{\mathrm{SMC}_{\mathrm{mod}}}\right)}{\sqrt{\sum_{\mathrm{i}=1}^{\mathrm{n}}\left(\mathrm{SMC}_{\mathrm{obs}, \mathrm{i}}-\overline{\mathrm{SMC}_{\mathrm{obs}}}\right)^{2}} \sqrt{\sum_{\mathrm{i}=1}^{\mathrm{n}}\left(\mathrm{SMC}_{\mathrm{mod}, \mathrm{i}}-\overline{\mathrm{SMC}_{\mathrm{mod}}}\right)^{2}}} \\
\mathrm{RMSE}=\sqrt{\frac{\sum_{\mathrm{i}=1}^{\mathrm{n}}\left(\mathrm{SMC}_{\mathrm{obs}, \mathrm{i}}-\mathrm{SMC}_{\mathrm{mod}, \mathrm{i}}\right)^{2}}{\mathrm{n}}}
\end{gathered}
$$

where, $\mathrm{SMC}_{\mathrm{obs}, \mathrm{i}}$ is the measured soil moisture value, $\mathrm{SMC}_{\bmod , \mathrm{i}}$ is the multiple linear regression fitted soil moisture value, $\mathrm{n}$ is the number of observations [22].

\section{Results and Discussions}

\subsection{Time Series NDVI and LST}

The NDVI dataset was the MOD13A2 product from 16 October 2013 to 29 September 2016. The product was the 16-day composite with a total of 69 images. $\mathrm{NDVI}_{\mathrm{AG}}$ (Figure $2 \mathrm{~b}$ ) was obtained by reconstructing the NDVI time series data with the AG algorithm, and then the $\mathrm{NDVI}_{\mathrm{AG}}$ and the original

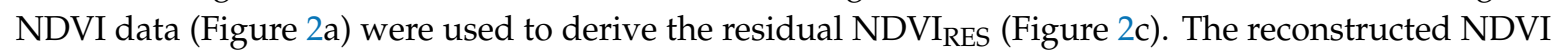
time series data $\left(\mathrm{NDVI}_{\mathrm{AG}}\right)$ based on the AG algorithm and the trend of the original NDVI time series data were basically the same (Figure 2d), and the reconstructed results were used to detect abnormally high and low values in the time series data, to correct the low values, and to reflect seasonal changes in the vegetation index [49]. The seasonal $\mathrm{NDVI}_{\mathrm{AG}}$ and the residual $\mathrm{NDVI}_{\mathrm{RES}}$ were consistent with the growth pattern of the vegetation [48].

The selected LST dataset was the MOD11A2 product from 16 October 2013 to 29 September 2016, which was an eight-day composite product with a total of 138 images. The eight-day LST dataset was converted to a 16-day LST images (Figure $3 b$ ) to match the NDVI temporal resolution by the MVC method [45]. 
a

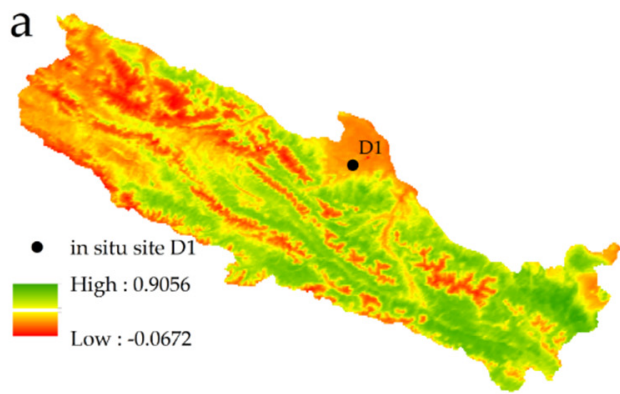

C

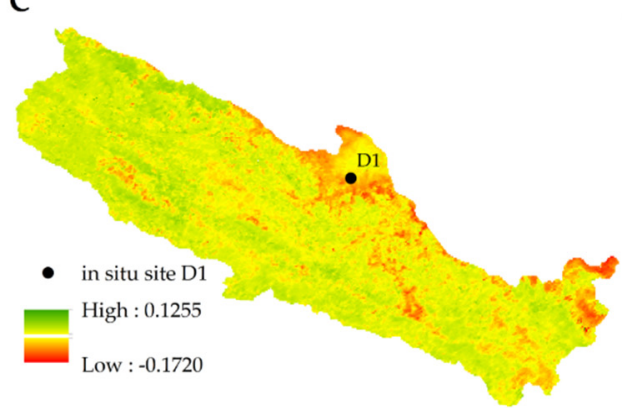

$\mathrm{b}$

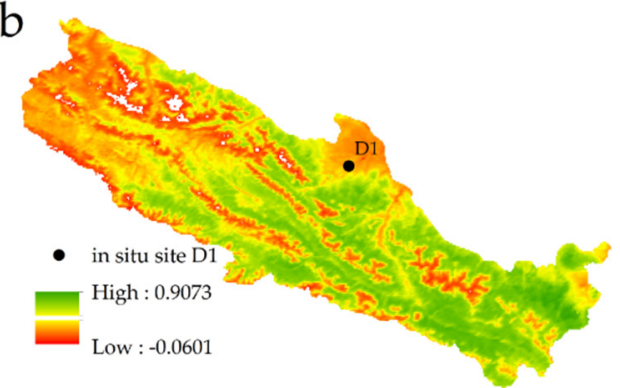

d

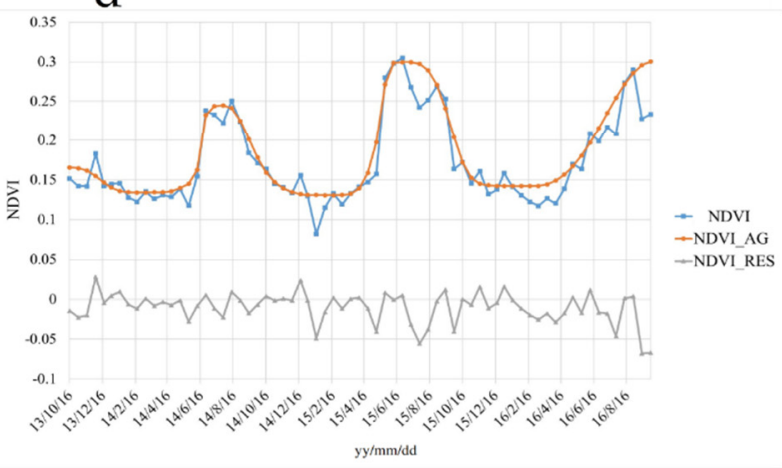

Figure 2. Vegetation Index (NDVI) in the study area. (a) The NDVI distribution and the location

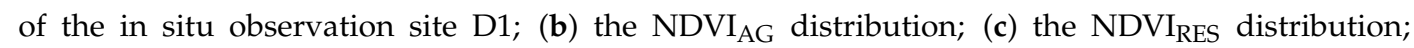
(d) the NDVI/NDVI ${ }_{\mathrm{AG}} / \mathrm{NDVI}_{\mathrm{RES}}$ change at the site D1.

a

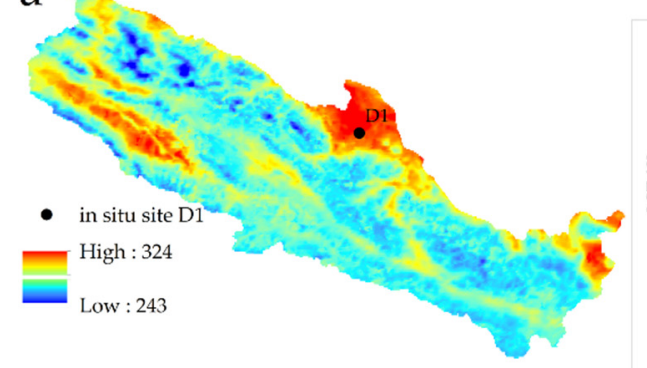

b

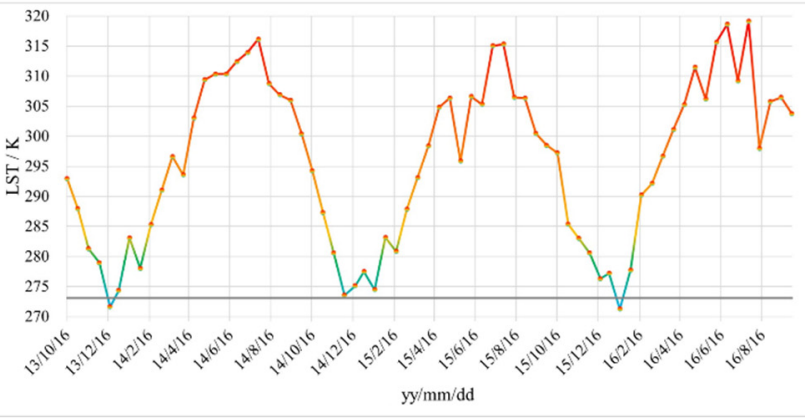

Figure 3. Land Surface Temperature (LST) data in the study area. (a) the LST distribution and the location of the in situ observation site D1; (b) the LST change at the site D1. The temperature is in Kelvin.

\subsection{Upscaling of In Situ Soil Moisture}

The soil moisture time series data in the 31 in situ observation sites were processed to 16-day mean values corresponding to the NDVI and LST's temporal resolution. Subsequently, multiple linear regressions were established between the in situ soil moisture observations and the NDVI and LST time series data. The five-layer soil moisture upscaling equation coefficients of the 31 in situ observation sites were shown in Tables 2 and A1, Tables A2-A4. For the $0-10 \mathrm{~cm}$ layer of the site D8, the soil moisture upscaling equation was significant at a 95\% confidence level, and all the other models at the rest 31 in situ observation sites were significant at a 99\% level. Among them, the correlation coefficient $\mathrm{R}$ of the $0-10 \mathrm{~cm}$ layer was $0.36-0.93$, the RMSE was 0.03 (Table 2); the R and RMSE of 10-20 cm layer were $0.65-0.90$, and 0.03 (Table A1), respectively; The R and RMSE of 20-30 cm layer were 0.51-0.95 and 0.03 (Table A2), respectively; the R and RMSE of 30-50 cm layer were $0.47-0.93$, and 0.03 (Table A3), 
respectively; and the R and RMSE of 50-70 cm layer were 0.54-0.94, and 0.02, respectively (Table A4). The accuracy of scaling results was higher than that of Xu et al. [21]. In general, the five-layer RMSE mean values were close to the $\mathrm{ECH} 2 \mathrm{O}$ data accuracy $\left(0.03 \mathrm{~cm}^{3} \mathrm{~cm}^{-3}\right)$, indicating that the accuracy of the in situ soil moisture estimation models was reasonable.

Table 2. Layer soil moisture estimation model $(0-10 \mathrm{~cm})$.

\begin{tabular}{|c|c|c|c|c|c|c|c|}
\hline Site & Intercept-a 0 & LST-a 1 & $\mathrm{NDVI}_{\text {RES }}-\mathrm{a}_{2}$ & $\mathrm{NDVI}_{\mathrm{AG}}-\mathbf{a}_{3}$ & F-Value & $\mathbf{R}$ & RMSE \\
\hline D1 & -0.1428 & 0.0006 & 0.4888 & 0.3638 & $27.1860 * *$ & 0.7564 & 0.0230 \\
\hline $\mathrm{D} 2$ & 0.1053 & -0.0003 & 0.1883 & 0.1883 & $42.9037 * *$ & 0.8151 & 0.0156 \\
\hline D3 & -0.0943 & 0.0004 & 0.5355 & 0.2924 & $9.1448^{* *}$ & 0.5448 & 0.0264 \\
\hline $\mathrm{D} 4$ & -0.1903 & 0.0008 & 0.3047 & 0.0796 & $21.4239 * *$ & 0.7051 & 0.0184 \\
\hline D5 & -0.3828 & 0.0017 & 0.0371 & 0.1482 & $24.7216^{* *}$ & 0.7300 & 0.0402 \\
\hline D6 & -0.2111 & 0.0009 & -0.0079 & 0.1728 & 13.7290 ** & 0.6721 & 0.0374 \\
\hline D7 & -0.1888 & 0.0007 & 0.1290 & 0.2629 & $41.9671^{* *}$ & 0.8121 & 0.0224 \\
\hline D8 & -0.1269 & 0.0006 & 0.1196 & 0.0833 & 3.2826 * & 0.3627 & 0.0348 \\
\hline D9 & -0.2464 & 0.0012 & -0.1120 & 0.1672 & $28.5156^{* *}$ & 0.7538 & 0.0384 \\
\hline D10 & -0.2147 & 0.0006 & 0.3632 & 0.6959 & 44.2519 ** & 0.8193 & 0.0278 \\
\hline D11 & -0.1179 & 0.0003 & 0.2781 & 0.2624 & $44.5027 * *$ & 0.8201 & 0.0316 \\
\hline D12 & -0.5345 & 0.0021 & 0.1640 & 0.1196 & $24.0405 * *$ & 0.8130 & 0.0284 \\
\hline D13 & -1.3622 & 0.0055 & -0.1438 & 0.0452 & $26.5764^{* *}$ & 0.7422 & 0.0693 \\
\hline D14 & -0.7388 & 0.0028 & -0.2080 & 0.0848 & $30.9407^{* *}$ & 0.8456 & 0.0284 \\
\hline D15 & -3.7797 & 0.0144 & -0.4288 & -0.1371 & $34.2043^{* *}$ & 0.7824 & 0.0986 \\
\hline D16 & -0.4971 & 0.0021 & 0.0441 & 0.0946 & 40.0270 ** & 0.8055 & 0.0294 \\
\hline D17 & -0.8997 & 0.0035 & 0.0051 & 0.3303 & $49.3673^{* *}$ & 0.8780 & 0.0464 \\
\hline D18 & -0.8674 & 0.0032 & -0.1961 & 0.0720 & $20.9669 * *$ & 0.7243 & 0.0426 \\
\hline D19 & -0.4460 & 0.0020 & -0.0038 & 0.0830 & $37.9425 * *$ & 0.7978 & 0.0313 \\
\hline D20 & -0.0336 & 0.0002 & 0.0248 & 0.2648 & $14.7577^{* *}$ & 0.6579 & 0.0326 \\
\hline D21 & -0.0005 & -0.0001 & 0.4719 & 0.8539 & $18.8724^{* *}$ & 0.7122 & 0.0208 \\
\hline $\mathrm{D} 22$ & -0.0523 & 0.0003 & 0.1973 & 0.2839 & $13.0625^{* *}$ & 0.6133 & 0.0183 \\
\hline $\mathrm{D} 23$ & -0.9314 & 0.0034 & 0.0434 & 0.2500 & $69.0881 * *$ & 0.8725 & 0.0308 \\
\hline D24 & -0.1344 & 0.0005 & 0.1318 & 0.2409 & 91.0531 ** & 0.9325 & 0.0194 \\
\hline D25 & -0.3850 & 0.0016 & 0.3814 & 0.2454 & $46.1557^{* *}$ & 0.8249 & 0.0271 \\
\hline $\mathrm{D} 26$ & -0.3739 & 0.0017 & 0.5105 & 0.1177 & $31.1755^{* *}$ & 0.7681 & 0.0319 \\
\hline $\mathrm{D} 27$ & -0.4618 & 0.0019 & 0.1124 & 0.0800 & $18.9346^{* *}$ & 0.6829 & 0.0352 \\
\hline D28 & -0.4352 & 0.0021 & 0.1503 & 0.1258 & $118.7521^{* *}$ & 0.9229 & 0.0175 \\
\hline D29 & -0.9221 & 0.0038 & -0.0596 & 0.1164 & $55.6932^{* *}$ & 0.8713 & 0.0366 \\
\hline D30 & -0.6680 & 0.0028 & 0.1740 & 0.1285 & $44.6734^{* *}$ & 0.8269 & 0.0290 \\
\hline D31 & -0.9122 & 0.0033 & 0.0739 & 0.3898 & $56.3416^{* *}$ & 0.8517 & 0.0589 \\
\hline
\end{tabular}

$*$ and ${ }^{* *}$ represent F-test significance level of $95 \%$ and $99 \%$, respectively. The table keeps 4 decimal places, the calculation keeps 8 decimal places. Intercept- $\mathrm{a}_{0}, \mathrm{LST}-\mathrm{a}_{1}, \mathrm{NDVI}_{\mathrm{RES}}-\mathrm{a}_{2}$ and $\mathrm{NDVI} \mathrm{AG}_{\mathrm{G}}-\mathrm{a}_{3}$ represent the coefficients of upscaling Equation (2). F-value means the significance value in the F-test. $\mathrm{R}$ is the complex correlation coefficient. RMSE is the root mean square error.

The soil moisture of each pixel (with spatial resolution of $1 \mathrm{~km}^{2}$ ) at the 31 zones from 16 October 2013 to 29 September 2016 was calculated by using the upscaling model to obtain the five-layer soil moisture dataset in the study area for the same study period. The dataset covered an area of $2.75 \times 10^{4} \mathrm{~km}^{2}$, with a temporal resolution of 16-day and a spatial resolution of $1 \mathrm{~km}^{2}$ (e.g., Figure 5).

\subsection{Accuracy Evaluation of Upscaling Soil Moisture Models}

To evaluate the accuracy of soil moisture upscaling models, the three sites-Biandukou, Dayekou and Kangle, which were not used to establish the regression equations, were used as validation sites, and their soil moisture data were used for correlation test and error analysis (Table 3). The results of the soil moisture upscaling in the different soil layers showed that the correlation coefficients were between 0.5410 and 0.8940 , and the RMSE were between 0.0066 and 0.0549 , all of which passed the F-test at $99 \%$ significant level. The results showed that the correlation between the upscaled data and 
the measured data were significant, and the soil moisture upscaling models well expressed the dry and wet conditions of the soil at the regional scale.

Table 3. Verification of the soil moisture upscaling equations at the three in situ observation sites.

\begin{tabular}{|c|c|c|c|c|c|}
\hline Layer & Site & $N$ & $\mathbf{R}$ & RMSE & F-Value \\
\hline \multirow{4}{*}{$0-10 \mathrm{~cm}$} & Biandukou & 48 & 0.6645 & 0.0373 & $36.3749 * *$ \\
\hline & Dayekou & 54 & 0.7247 & 0.0417 & $57.5060^{* *}$ \\
\hline & Kangle & 54 & 0.6766 & 0.0247 & $43.9005^{* *}$ \\
\hline & mean & & 0.6886 & 0.0346 & $45.9271^{* *}$ \\
\hline \multirow{4}{*}{$10-20 \mathrm{~cm}$} & Biandukou & 55 & 0.7366 & 0.0255 & $62.8749^{* *}$ \\
\hline & Dayekou & 54 & 0.6310 & 0.0549 & $34.4064^{* *}$ \\
\hline & Kangle & 49 & 0.7981 & 0.0127 & $82.4391^{* *}$ \\
\hline & mean & & 0.7219 & 0.0310 & $59.9068^{* *}$ \\
\hline \multirow{4}{*}{$20-30 \mathrm{~cm}$} & Biandukou & 55 & 0.7172 & 0.0258 & $56.1386^{* *}$ \\
\hline & Dayekou & 54 & 0.7455 & 0.0275 & $65.0525^{* *}$ \\
\hline & Kangle & 54 & 0.8376 & 0.0106 & $122.2273^{* *}$ \\
\hline & mean & & 0.7668 & 0.0213 & $81.1394^{* *}$ \\
\hline \multirow{4}{*}{$30-50 \mathrm{~cm}$} & Biandukou & 55 & 0.5410 & 0.0339 & $21.9261^{* *}$ \\
\hline & Dayekou & 54 & 0.5908 & 0.0342 & $27.8885^{* *}$ \\
\hline & Kangle & 53 & 0.8940 & 0.0066 & $203.0996^{* *}$ \\
\hline & mean & & 0.6753 & 0.0249 & $84.3048^{* *}$ \\
\hline \multirow{4}{*}{$50-70 \mathrm{~cm}$} & Biandukou & 30 & 0.5254 & 0.0338 & $10.6759^{* *}$ \\
\hline & Dayekou & 54 & 0.6441 & 0.0247 & $36.8675^{* *}$ \\
\hline & Kangle & 54 & 0.8187 & 0.0094 & $105.6833^{* *}$ \\
\hline & mean & & 0.6627 & 0.0226 & $51.0756^{* *}$ \\
\hline \multirow{3}{*}{ total } & \multicolumn{2}{|c|}{ Biandukou } & 0.6369 & 0.0313 & $37.5981^{* *}$ \\
\hline & \multicolumn{2}{|c|}{ Dayekou } & 0.6672 & 0.0366 & $44.3442^{* *}$ \\
\hline & \multicolumn{2}{|c|}{ Kangle } & 0.8050 & 0.0128 & $111.4700^{* *}$ \\
\hline
\end{tabular}

${ }^{* *}$ means F-test at $99 \%$ significance. $N$ is the observations.

Comparing the validation results of soil moisture models of the five layers, we found that the R's descending order was 20-30 cm $>10-20 \mathrm{~cm}>0-10 \mathrm{~cm}>30-50 \mathrm{~cm}>50-70 \mathrm{~cm}$, RMSE's descending order was 0-10 cm $>10-20 \mathrm{~cm}>30-50 \mathrm{~cm}>50-70 \mathrm{~cm}>20-30 \mathrm{~cm}$. The trends of the two indices were not consistent, the main reason might be: 1) the variability of soil moisture with time decreased from the top to the bottom soil layer, and the $0-10 \mathrm{~cm}$ layer had the largest soil water fluctuation and the largest error, 2) the LST was mainly affected by the $0-10 \mathrm{~cm}$ layer of soil and overlying vegetation, 3) NDVI was mainly affected by the vegetation growth, and the root zone soil moisture was very important for vegetation growth, the main vegetation types of the three verification sites were all grassland, with their root system mainly distributed in the $20-30 \mathrm{~cm}$. Therefore, the accuracy of the 20-30 cm soil moisture upscaling model was the highest, and the lowest was the 50-70 cm layer.

Comparison of the soil moisture upscaling results of the three verification sites showed that the RMSE values were getting smaller from the top to the deep soil layers, Kangle appeared to have the best fit. Topographically, the Kangle site was located at a plateau within $1 \mathrm{~km}^{2}$ pixels. The vegetation type was mainly grass (Stipa Steppe) with homogeneous distribution. The climate was dry, with smaller rainfall (annual $338 \mathrm{~mm}$ for Kangle, $428 \mathrm{~mm}$ for Dayekou and $702 \mathrm{~mm}$ for Biandukou during the 2013-2016 period), the soil moisture was relatively low and stable. Under these climate, topography and vegetation conditions, the LST and NDVI data were of relatively high quality, and the accuracy of the upscaling was high. The Biandukou and Dayekou sites were located on the mountain slope. The terrain was complex within $1 \mathrm{~km}^{2}$ pixels, and the vegetation types were diverse. In addition, there was a reservoir near the Dayekou site. These factors were likely to have affected the LST and NDVI quality of remote sensing products, and the accuracy of the upscaling model was not as good as that of the Kangle site. 


\subsection{Soil Moisture Variability at Different Temporal and Spatial Scales}

\subsubsection{Temporal Variability of Soil Moisture at the Regional Scale}

Figure 4 shows the changes in soil moisture at different layers over time. As Figure 4 a shows, the soil moisture was the lowest in December and the highest in July. The descending soil moisture order in all the layers in December were 20-30 cm > 50-70 cm $>10-20 \mathrm{~cm}>30-50 \mathrm{~cm}>0-10 \mathrm{~cm}$. The descending soil moisture order in all the layers in July were 20-30 cm $>10-20 \mathrm{~cm}>0-10 \mathrm{~cm}>$ $30-50 \mathrm{~cm}>50-70 \mathrm{~cm}$. Among them, the 20-30 cm were the highest among all the layers of the soil profile. During the whole three years, the variation range of each layer was $0-10 \mathrm{~cm}$ (coefficient of variation, CV. 12.44\%), 10-20 cm (CV. 12.27\%), 20-30 cm (CV. 11.86\%), 30-50 cm (CV. 10.40\%), 50-70 cm (CV. 8.38\%), respectively, which was closely related to the effects of precipitation and soil infiltration on soil moisture. Figure $4 \mathrm{~b}$ shows that the $20-30 \mathrm{~cm}$ and $30-50 \mathrm{~cm}$ had a relatively high and low but stable variation. Among the four seasons, the precipitation and temperature were low in winter, leading to the decrease of liquid water in the soil, thus the soil moisture was the lowest in the winter. Summer rainfall was the highest and most frequent, therefore the soil moisture content was highest and most variable in the summer.

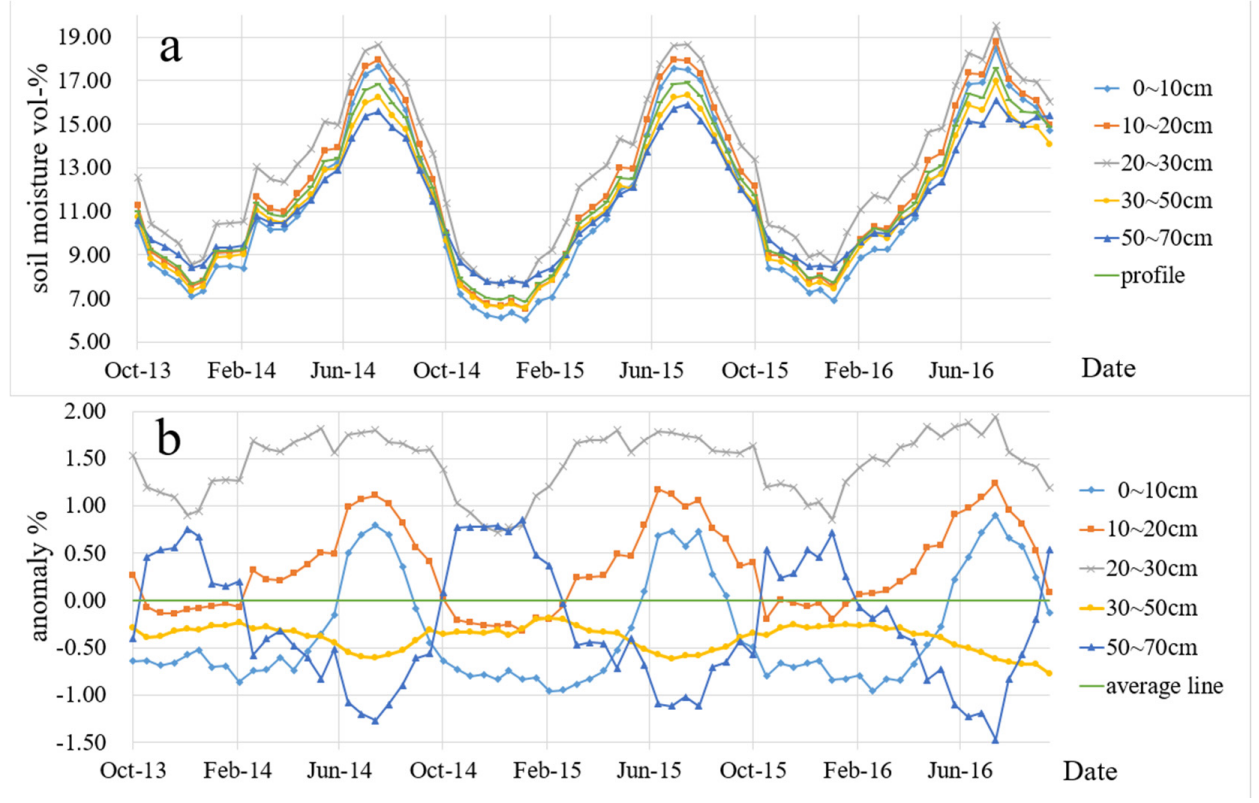

Figure 4. Temporal variability of soil moisture. (a) temporal variability of soil moisture in real value; (b) anomaly between each layer and the mean soil moisture.

\subsubsection{Spatial Distribution of Soil Moisture at the Regional Scale}

The overall spatial distribution of soil moisture during the growing season from 2014 to 2016 are shown in Figure 5. The weighted mean soil moisture of the three years was $14.50 \%$ in the entire study region. Soil moisture was higher in most of the eastern, central and northwestern parts of the region. Overall, the soil moisture in the eastern area was generally higher than that in the central and western areas, and the soil moisture was the lowest in the western area. The spatial patterns were consistent with the precipitation distribution pattern shown in Figure $5 \mathrm{~d}$ and Tian et al. [42]. The precipitation during the growth period of 2014 to 2016 was highest in the Biandukou, the second highest in the Dayekou, and the lowest in the Kangle automatic weather station, showing a spatial pattern of a declining trend from the eastern to the central and to the western parts of the region. Since the limited number of automatic weather stations and coarse spatial coverage, the precipitation was not incorporated into the regression analysis. 

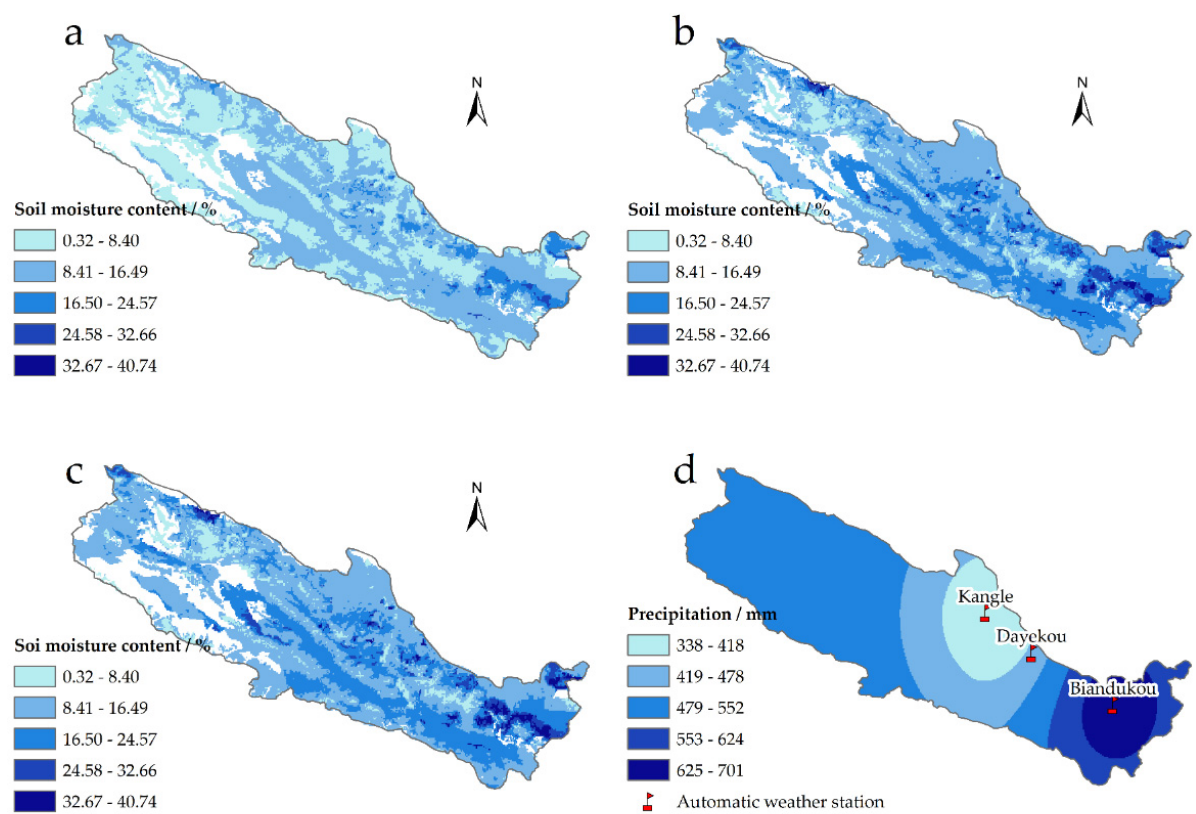

Figure 5. Spatial distribution of soil moisture during the 2014-2016 growth period. (a) 2014 growth period; (b) 2015 growth period; (c) 2016 growth period; (d) rainfall distribution pattern by kriging interpolation based on data obtained from the three automatic weather stations during the 2014-2016 period.

\subsubsection{Soil Profile Moisture Heterogeneity at the Regional Scale}

As shown in Figure 6, soil moisture and its variability at different layers were shown by the relationship between the mean and coefficient of variation (CV). The fitting curves indicated that the variability of soil moisture at the shallow layers was larger than deeper layers. Mean and CV had negative correlations in the $30-50 \mathrm{~cm}$ and $50-70 \mathrm{~cm}$ layers, indicating that the soil moisture variability was the highest in dry conditions and the lowest in humid conditions (e.g., summer), and the fitting curve between the $30-50 \mathrm{~cm}$ layers and the whole profile was close, indicating that the characteristics of the soil moisture change in the $30-50 \mathrm{~cm}$ was similar to that of the whole profile. As described in the above section, the most representative of the whole profile was $30-50 \mathrm{~cm}$ among the five layers.

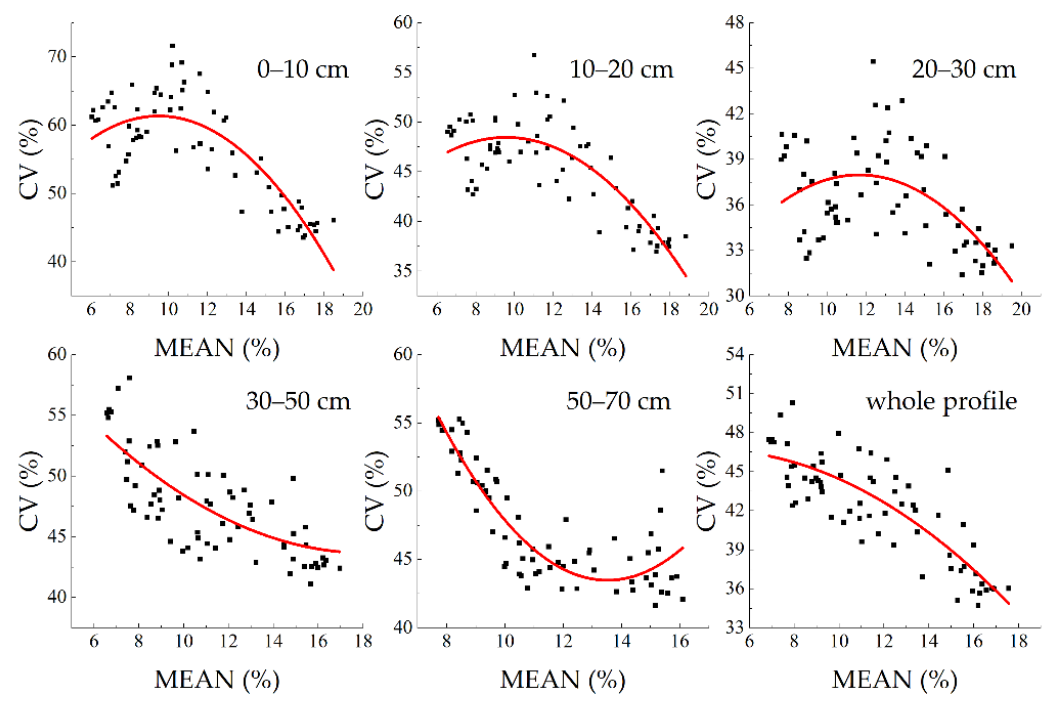

Figure 6. Mean and coefficient of variation $(\mathrm{CV})$ of soil moisture at different layers. 


\section{Conclusions}

Estimating spatial and temporal distribution of soil moisture is a challenge in high-elevation, data-scarce, and heterogeneous mountainous areas like the upstream of the Heihe River Watershed in Northwest China. We proposed a regression model based on the MODIS NDVI and LST to estimate profile soil moisture at the regional scale. Subsequently, we analyzed the spatial and temporal variability of soil moisture at the regional scale. Results showed that the multivariate linear regression method could be used to estimate high-resolution soil moisture products in alpine and cold mountainous areas at both shallow and deep soil layers. The soil moisture in the east of the upstream of the Heihe River Watershed was significantly higher than that in the west, and the average soil moisture in the whole region was $14.5 \%$ in the $0-70 \mathrm{~cm}$ depth. The soil moisture at the $30-50 \mathrm{~cm}$ soil layer could reasonably represent the $0-70 \mathrm{~cm}$ profile soil moisture. Soil moisture in the $0-10 \mathrm{~cm}$ layer had the highest variability while the $20-30 \mathrm{~cm}$ layer showed the lowest soil moisture variability among all the layers. The contribution of this study was to estimate profile soil moisture at the regional scale by readily available remote sensing products of NDVI and LST.

However, the microterrain features such as slope and aspect were not considered in the soil-vegetation-elevation sampling zone, which might affect the accuracy of soil moisture upscaling models. Satellite products with high spatial-temporal resolutions need to be integrated with in situ observations and other soil and vegetation datasets to improve the accuracy of estimating soil moisture at the regional scale, especially in data-scarce and topographically complex mountainous regions.

Author Contributions: Conceptualization, X.B., L.Z. and C.H.; field work: X.B. and Y.Z.; processing and analysis, X.B. and L.Z.; writing-original draft preparation, X.B. and L.Z.; review, editing, and finalization, C.H.; project administration, C.H. All authors have read and agreed to the published version of the manuscript.

Funding: The project is partially funded by the grants from National Natural Science Foundation of China (41530752, 41877148, 41501016 and 91125010).

Acknowledgments: We are grateful to the members of the Center for Dryland Water Resources Research and Watershed Science, Lanzhou University for their hard field work to collect and analyze the soil data in the high and cold, hard to reach mountainous areas over the past seven years. Meanwhile, we are deeply grateful to the anonymous reviewers and Section Managing Editor Muriel Zhang for their constructive comments and responsible work.

Conflicts of Interest: The authors declare no conflict of interest. 


\section{Appendix A}

Table A1. Layer soil moisture estimation model $(10-20 \mathrm{~cm})$.

\begin{tabular}{|c|c|c|c|c|c|c|c|}
\hline Site & Intercept-a & LST-a & $\mathrm{NDVI}_{\text {RES }}-\mathrm{a}_{2}$ & $\mathrm{NDVI}_{\mathrm{AG}}-\mathrm{a}_{3}$ & F-Value & $\mathbf{R}$ & RMSE \\
\hline D1 & -0.0448 & 0.0003 & 0.1239 & 0.1552 & $47.1598^{* *}$ & 0.8359 & 0.0082 \\
\hline D2 & 0.0356 & 0.0000 & 0.1810 & 0.1748 & $38.1284^{* *}$ & 0.7985 & 0.0170 \\
\hline D3 & -0.2269 & 0.0008 & 0.4974 & 0.6081 & $45.2227^{* *}$ & 0.8222 & 0.0224 \\
\hline D4 & -0.1502 & 0.0007 & 0.0725 & 0.0469 & $62.7791 * *$ & 0.8798 & 0.0079 \\
\hline D5 & -0.4594 & 0.0020 & -0.0527 & 0.0761 & $25.6997^{* *}$ & 0.7366 & 0.0294 \\
\hline D6 & -0.1641 & 0.0008 & -0.0593 & 0.1495 & $12.7288^{* *}$ & 0.6580 & 0.0351 \\
\hline D7 & -0.0033 & 0.0000 & 0.2733 & 0.4083 & $44.2384^{* *}$ & 0.8193 & 0.0271 \\
\hline D8 & -0.3441 & 0.0015 & 0.2253 & 0.2215 & $37.5842 * *$ & 0.7964 & 0.0256 \\
\hline D9 & -0.3716 & 0.0016 & 0.0603 & 0.1356 & $41.7135^{* *}$ & 0.8113 & 0.0313 \\
\hline D10 & -0.3128 & 0.0012 & 0.2242 & 0.4499 & $61.1032^{* *}$ & 0.8592 & 0.0204 \\
\hline D11 & -0.0782 & 0.0003 & 0.2959 & 0.2660 & $60.4343^{* *}$ & 0.8580 & 0.0276 \\
\hline D12 & -0.5718 & 0.0022 & 0.1828 & 0.0993 & $26.5246^{* *}$ & 0.8262 & 0.0266 \\
\hline D13 & -0.6246 & 0.0028 & -0.2230 & 0.1037 & $25.5179 * *$ & 0.7354 & 0.0561 \\
\hline D14 & -0.7640 & 0.0030 & -0.3891 & 0.0782 & $21.1450 * *$ & 0.7947 & 0.0345 \\
\hline D15 & -3.1465 & 0.0121 & -0.3682 & -0.1379 & $49.6064^{* *}$ & 0.8343 & 0.0655 \\
\hline D16 & -0.5756 & 0.0025 & -0.0085 & 0.1084 & $31.9732 * *$ & 0.7721 & 0.0388 \\
\hline D17 & -0.6236 & 0.0024 & -0.0017 & 0.4309 & $38.3976^{* *}$ & 0.8507 & 0.0587 \\
\hline D18 & -0.6764 & 0.0027 & -0.1042 & 0.0408 & $22.3538^{* *}$ & 0.7126 & 0.0330 \\
\hline D19 & -0.4705 & 0.0020 & -0.0212 & 0.0813 & $36.9206^{* *}$ & 0.7938 & 0.0313 \\
\hline D20 & 0.0072 & 0.0001 & 0.0309 & 0.2423 & $18.7568^{* *}$ & 0.7017 & 0.0256 \\
\hline D21 & 0.0465 & -0.0003 & 0.2537 & 0.9154 & $19.9186^{* *}$ & 0.7216 & 0.0205 \\
\hline D22 & -0.0461 & 0.0002 & 0.1433 & 0.4214 & $33.0572 * *$ & 0.7772 & 0.0153 \\
\hline D23 & -0.8592 & 0.0032 & 0.0515 & 0.2168 & $68.1222^{* *}$ & 0.8710 & 0.0283 \\
\hline D24 & 0.0002 & 0.0000 & 0.0661 & 0.1138 & $18.7331^{* *}$ & 0.7604 & 0.0185 \\
\hline D25 & -0.4217 & 0.0018 & 0.3830 & 0.1929 & $49.7008^{* *}$ & 0.8345 & 0.0243 \\
\hline D26 & -0.4072 & 0.0017 & 0.5010 & 0.1211 & $37.0421^{* *}$ & 0.7943 & 0.0300 \\
\hline D27 & -0.4132 & 0.0016 & 0.0655 & 0.0041 & $15.6931^{* *}$ & 0.6481 & 0.0243 \\
\hline D28 & -0.3328 & 0.0016 & 0.2332 & 0.1694 & $66.8502 * *$ & 0.8740 & 0.0250 \\
\hline D29 & -1.4304 & 0.0057 & -0.1453 & 0.0258 & $37.4054^{* *}$ & 0.8241 & 0.0436 \\
\hline D30 & -0.7721 & 0.0031 & 0.1355 & 0.0902 & $50.5135^{* *}$ & 0.8366 & 0.0265 \\
\hline D31 & -0.8850 & 0.0034 & 0.0180 & 0.1557 & $95.4179 * *$ & 0.9040 & 0.0253 \\
\hline
\end{tabular}

** represents F-test significance level of $99 \%$. The table keeps 4 decimal places, the calculation keeps 8 decimal

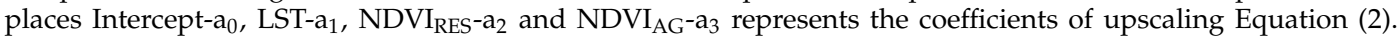
F-value means the significance value in the F-test. $R$ is the complex correlation coefficient. RMSE is the root mean square error. 
Table A2. Layer soil moisture estimation model $(20-30 \mathrm{~cm})$.

\begin{tabular}{|c|c|c|c|c|c|c|c|}
\hline Site & Intercept- $\mathrm{a}_{0}$ & LST-a 1 & 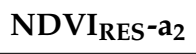 & $\mathrm{NDVI}_{\mathrm{AG}} \mathbf{- a}_{3}$ & F-Value & $\mathbf{R}$ & RMSE \\
\hline D1 & -0.0083 & 0.0002 & 0.0743 & 0.2354 & $41.1005^{* *}$ & 0.8224 & 0.0111 \\
\hline D2 & -0.1153 & 0.0007 & 0.0931 & 0.1193 & $34.1421 * *$ & 0.7822 & 0.0172 \\
\hline D3 & -0.0706 & 0.0004 & 0.0280 & 0.1362 & $106.4698^{* *}$ & 0.9115 & 0.0045 \\
\hline D4 & -0.1461 & 0.0007 & 0.0442 & 0.0442 & $81.4475^{* *}$ & 0.9158 & 0.0058 \\
\hline D5 & -0.4863 & 0.0021 & -0.0769 & 0.0640 & $42.4492 * *$ & 0.8137 & 0.0223 \\
\hline D6 & -0.1669 & 0.0008 & -0.0583 & 0.1072 & $10.6971^{* *}$ & 0.6252 & 0.0315 \\
\hline D7 & -0.1960 & 0.0009 & 0.1118 & 0.2254 & $68.0018^{* *}$ & 0.8791 & 0.0164 \\
\hline D8 & -0.2864 & 0.0013 & 0.2385 & 0.2561 & $73.0847^{* *}$ & 0.8783 & 0.0181 \\
\hline D9 & -0.3968 & 0.0018 & 0.0137 & 0.0914 & $35.6686^{* *}$ & 0.7887 & 0.0300 \\
\hline D10 & -0.1977 & 0.0009 & 0.1481 & 0.4672 & $97.0527 * *$ & 0.9042 & 0.0148 \\
\hline D11 & -0.2159 & 0.0009 & 0.2404 & 0.2235 & $76.6659 * *$ & 0.8830 & 0.0230 \\
\hline D12 & -0.4539 & 0.0019 & 0.1899 & 0.0817 & $30.0917 * *$ & 0.8422 & 0.0211 \\
\hline D13 & -0.6281 & 0.0028 & -0.2828 & 0.1395 & $20.4940^{* *}$ & 0.6972 & 0.0736 \\
\hline D14 & -1.2032 & 0.0047 & -0.5466 & 0.1281 & $28.3354^{* *}$ & 0.8347 & 0.0474 \\
\hline D15 & -2.9820 & 0.0116 & -0.3259 & -0.1956 & $28.7933^{* *}$ & 0.7554 & 0.0724 \\
\hline D16 & -0.5306 & 0.0023 & -0.0735 & 0.0654 & $15.8860^{* *}$ & 0.6504 & 0.0431 \\
\hline D17 & -0.4574 & 0.0019 & 0.1621 & 0.3431 & $36.6091^{* *}$ & 0.8450 & 0.0467 \\
\hline D18 & -0.4233 & 0.0018 & -0.1834 & 0.0218 & $7.6475^{* *}$ & 0.5108 & 0.0373 \\
\hline D19 & -0.4601 & 0.0019 & -0.0253 & 0.0735 & $40.5132^{* *}$ & 0.8072 & 0.0280 \\
\hline D20 & 0.0795 & -0.0001 & 0.1087 & 0.2177 & $25.5517^{* *}$ & 0.7545 & 0.0182 \\
\hline D21 & 0.0384 & -0.0002 & 0.1139 & 0.8839 & $25.9263^{* *}$ & 0.7654 & 0.0180 \\
\hline D22 & -0.0273 & 0.0002 & 0.1510 & 0.3218 & $15.9146^{* *}$ & 0.6596 & 0.0162 \\
\hline D23 & -0.8016 & 0.0032 & 0.0669 & 0.1044 & $77.8980^{* *}$ & 0.8845 & 0.0212 \\
\hline D24 & -0.2004 & 0.0007 & 0.0031 & 0.0648 & $137.3034^{* *}$ & 0.9537 & 0.0058 \\
\hline D25 & -0.4723 & 0.0019 & 0.4172 & 0.1751 & $47.0887^{* *}$ & 0.8462 & 0.0224 \\
\hline D26 & -0.4483 & 0.0020 & 0.4454 & 0.0871 & $35.3780 * *$ & 0.7875 & 0.0288 \\
\hline D27 & -0.2725 & 0.0011 & 0.0413 & 0.0380 & $23.8688^{* *}$ & 0.7240 & 0.0174 \\
\hline D28 & -0.3072 & 0.0015 & 0.1535 & 0.1483 & $78.3862 * *$ & 0.8896 & 0.0207 \\
\hline D29 & -1.7187 & 0.0068 & -0.2184 & 0.0185 & 30.9722 ** & 0.7980 & 0.0554 \\
\hline D30 & -0.7217 & 0.0029 & 0.1286 & 0.0932 & $48.8410^{* *}$ & 0.8323 & 0.0261 \\
\hline D31 & -0.9337 & 0.0034 & -0.0136 & 0.1848 & $51.1559^{* *}$ & 0.8401 & 0.0385 \\
\hline
\end{tabular}

** represents F-test significance level of $99 \%$. The table keeps 4 decimal places, the calculation keeps 8 decimal places. 
Table A3. Layer soil moisture estimation model $(30-50 \mathrm{~cm})$.

\begin{tabular}{|c|c|c|c|c|c|c|c|}
\hline Site & Intercept- $\mathrm{a}_{0}$ & LST-a 1 & 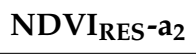 & $\mathrm{NDVI}_{\mathrm{AG}} \mathbf{- a}_{3}$ & F-Value & $\mathbf{R}$ & RMSE \\
\hline D1 & -0.0014 & 0.0003 & -0.0091 & 0.0181 & $4.6020^{* *}$ & 0.4652 & 0.0095 \\
\hline D2 & -0.0332 & 0.0003 & 0.0570 & 0.0953 & $26.3842 * *$ & 0.7410 & 0.0140 \\
\hline D3 & -0.0842 & 0.0005 & 0.0172 & 0.0802 & $147.0702 * *$ & 0.9336 & 0.0036 \\
\hline D4 & -0.1455 & 0.0007 & 0.0316 & 0.0330 & $95.5330 * *$ & 0.9028 & 0.0058 \\
\hline D5 & -0.4512 & 0.0020 & -0.1234 & 0.0728 & $48.8376^{* *}$ & 0.8323 & 0.0213 \\
\hline D6 & -0.2033 & 0.0010 & -0.0737 & 0.0705 & $10.6289^{* *}$ & 0.6240 & 0.0277 \\
\hline D7 & -0.3535 & 0.0014 & 0.1489 & 0.2710 & $100.0371^{* *}$ & 0.9066 & 0.0188 \\
\hline D8 & -0.2611 & 0.0013 & 0.0147 & 0.1866 & $107.5899 * *$ & 0.9123 & 0.0132 \\
\hline D9 & -0.3237 & 0.0013 & 0.1924 & 0.0761 & $6.2735^{* *}$ & 0.4826 & 0.0567 \\
\hline D10 & -0.1469 & 0.0007 & 0.0054 & 0.3318 & $103.2531 * *$ & 0.9092 & 0.0108 \\
\hline D11 & -0.0180 & 0.0002 & 0.1437 & 0.2159 & $22.7155^{* *}$ & 0.7154 & 0.0353 \\
\hline D12 & -0.1346 & 0.0008 & 0.0908 & 0.0537 & $14.4754^{* *}$ & 0.7348 & 0.0149 \\
\hline D13 & -0.3398 & 0.0016 & -0.1759 & 0.1285 & $19.0697^{* *}$ & 0.7047 & 0.0547 \\
\hline D14 & -0.7170 & 0.0030 & -0.3272 & 0.0878 & $18.6426^{* *}$ & 0.7758 & 0.0381 \\
\hline D15 & -1.7513 & 0.0071 & -0.2116 & 0.0450 & $35.0906^{* *}$ & 0.7863 & 0.0667 \\
\hline D16 & -0.3874 & 0.0017 & -0.1079 & 0.0567 & $6.9133^{* *}$ & 0.4918 & 0.0526 \\
\hline D17 & -0.4576 & 0.0019 & 0.1425 & 0.4975 & $39.1722 * *$ & 0.8530 & 0.0618 \\
\hline D18 & -0.3296 & 0.0016 & -0.0880 & 0.0489 & $12.7872^{* *}$ & 0.6092 & 0.0322 \\
\hline D19 & -0.3036 & 0.0013 & -0.0353 & 0.0737 & $34.1784^{* *}$ & 0.7823 & 0.0263 \\
\hline D20 & -0.0590 & 0.0004 & 0.0769 & 0.1023 & $25.2061^{* *}$ & 0.7523 & 0.0131 \\
\hline D21 & 0.0503 & -0.0002 & 0.0502 & 0.6640 & $20.0755^{* *}$ & 0.7230 & 0.0153 \\
\hline D22 & -0.0449 & 0.0002 & -0.0200 & 0.7046 & $31.0264^{* *}$ & 0.7673 & 0.0259 \\
\hline D23 & -0.5755 & 0.0022 & 0.0430 & 0.1652 & $70.6508^{* *}$ & 0.8748 & 0.0202 \\
\hline D24 & -0.2131 & 0.0008 & 0.0179 & 0.1207 & $70.9558^{* *}$ & 0.9157 & 0.0128 \\
\hline D25 & -0.4455 & 0.0019 & 0.2208 & 0.1388 & $54.0855^{* *}$ & 0.8450 & 0.0211 \\
\hline D26 & -0.4102 & 0.0019 & 0.4669 & 0.1138 & $30.2195^{* *}$ & 0.7632 & 0.0331 \\
\hline D27 & -0.3371 & 0.0014 & 0.0287 & 0.0524 & $21.2821^{* *}$ & 0.7039 & 0.0233 \\
\hline D28 & -0.0846 & 0.0007 & 0.1239 & 0.1617 & $60.3166^{* *}$ & 0.8757 & 0.0202 \\
\hline D29 & -1.6336 & 0.0064 & -0.2181 & 0.0271 & $34.8192 * *$ & 0.8145 & 0.0503 \\
\hline D30 & -0.6545 & 0.0026 & 0.0989 & 0.0839 & $42.3720^{* *}$ & 0.8134 & 0.0249 \\
\hline D31 & -0.5294 & 0.0022 & 0.0122 & 0.2322 & $46.7052^{* *}$ & 0.8285 & 0.0399 \\
\hline
\end{tabular}

** represents F-test significance level of $99 \%$. The table keeps 4 decimal places, the calculation keeps 8 decimal places. 
Table A4. The 50-70 cm layer soil moisture estimation model.

\begin{tabular}{|c|c|c|c|c|c|c|c|}
\hline Site & Intercept- $\mathrm{a}_{0}$ & LST-a 1 & 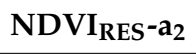 & $\mathrm{NDVI}_{\mathrm{AG}} \mathbf{- a}_{3}$ & F-Value & $\mathbf{R}$ & RMSE \\
\hline D1 & 0.0253 & 0.0001 & -0.0361 & 0.1726 & $19.3090 * *$ & 0.6979 & 0.0123 \\
\hline D2 & -0.1375 & 0.0007 & 0.0425 & 0.1023 & $38.1098^{* *}$ & 0.7985 & 0.0152 \\
\hline D3 & -0.0882 & 0.0005 & 0.0236 & 0.0765 & 155.1495 ** & 0.9367 & 0.0036 \\
\hline D4 & -0.1493 & 0.0007 & 0.0231 & 0.0354 & $120.8715^{* *}$ & 0.9209 & 0.0054 \\
\hline D5 & -0.3495 & 0.0016 & -0.1239 & 0.0601 & $33.9899 * *$ & 0.7815 & 0.0208 \\
\hline D6 & -0.3934 & 0.0018 & -0.0707 & -0.0019 & $20.0979^{* *}$ & 0.7394 & 0.0219 \\
\hline D7 & -0.1164 & 0.0006 & 0.0633 & 0.0714 & $112.0099 * *$ & 0.9154 & 0.0060 \\
\hline D8 & -0.0750 & 0.0008 & -0.0578 & 0.1556 & $126.9255^{* *}$ & 0.9242 & 0.0090 \\
\hline D9 & -0.2302 & 0.0012 & -0.1346 & 0.0672 & $20.0882 * *$ & 0.6964 & 0.0278 \\
\hline D10 & -0.0524 & 0.0003 & -0.2237 & 0.3529 & $90.7162 * *$ & 0.8998 & 0.0113 \\
\hline D11 & 0.0185 & 0.0002 & 0.1235 & 0.1380 & $19.0389 * *$ & 0.6839 & 0.0255 \\
\hline D12 & -0.1324 & 0.0008 & 0.0654 & 0.0170 & $20.7468^{* *}$ & 0.7919 & 0.0089 \\
\hline D13 & -0.3579 & 0.0017 & -0.0768 & 0.1460 & $23.4037^{* *}$ & 0.7206 & 0.0563 \\
\hline D14 & -0.4018 & 0.0017 & -0.2710 & 0.0489 & $9.4123 * *$ & 0.6579 & 0.0295 \\
\hline D15 & -0.5082 & 0.0024 & -0.0496 & 0.2065 & $27.0967^{* *}$ & 0.7480 & 0.0667 \\
\hline D16 & -0.0781 & 0.0007 & -0.1116 & 0.1095 & $8.8637^{* *}$ & 0.5388 & 0.0458 \\
\hline D17 & -0.2471 & 0.0010 & 0.1567 & 0.2524 & $24.4479^{* *}$ & 0.7906 & 0.0395 \\
\hline D18 & -0.0561 & 0.0007 & 0.0170 & 0.0606 & $12.1061^{* *}$ & 0.5987 & 0.0263 \\
\hline D19 & -0.2337 & 0.0011 & -0.0544 & 0.0720 & $32.4551^{* *}$ & 0.7744 & 0.0250 \\
\hline D20 & -0.1091 & 0.0005 & 0.0369 & 0.1078 & $22.2550^{* *}$ & 0.7315 & 0.0150 \\
\hline D21 & 0.0981 & -0.0004 & -0.1776 & 0.9557 & $12.3260^{* *}$ & 0.6341 & 0.0281 \\
\hline D22 & 0.0150 & 0.0001 & -0.0915 & 0.5681 & $21.8802^{* *}$ & 0.7088 & 0.0245 \\
\hline D23 & -0.5426 & 0.0021 & 0.0358 & 0.1850 & $51.7100 * *$ & 0.8395 & 0.0238 \\
\hline D24 & -0.0146 & 0.0000 & 0.0540 & 0.0580 & $4.5765^{* *}$ & 0.5540 & 0.0159 \\
\hline D25 & -0.2784 & 0.0012 & 0.0099 & 0.1675 & $40.9908^{* *}$ & 0.8088 & 0.0210 \\
\hline D26 & -0.0808 & 0.0003 & 0.1109 & 0.0342 & $13.1810^{* *}$ & 0.6150 & 0.0117 \\
\hline D27 & -0.1480 & 0.0007 & 0.0198 & 0.0610 & $26.5345^{* *}$ & 0.7420 & 0.0142 \\
\hline D28 & -0.2307 & 0.0012 & 0.1268 & 0.1033 & $34.8308^{* *}$ & 0.7922 & 0.0229 \\
\hline D29 & -0.4168 & 0.0020 & -0.0756 & 0.0395 & $20.0238^{* *}$ & 0.7289 & 0.0274 \\
\hline D30 & -0.6083 & 0.0025 & 0.0864 & 0.0694 & $48.0417^{* *}$ & 0.8302 & 0.0212 \\
\hline D31 & -0.4414 & 0.0019 & 0.0115 & 0.1648 & $43.6817^{* *}$ & 0.8218 & 0.0308 \\
\hline
\end{tabular}

** represents F-test significance level of $99 \%$. The table keeps 4 decimal places, the calculation keeps 8 decimal places.

\section{References}

1. Vereecken, H.; Huisman, J.A.; Franssen, H.H.; Bruggemann, N.; Bogena, H.; Kollet, S.; Javaux, M.; Der Kruk, J.V.; Vanderborght, J. Soil hydrology: Recent methodological advances, challenges, and perspectives. Water Resour. Res. 2015, 51, 2616-2633. [CrossRef]

2. Vereecken, H.; Huisman, J.A.; Bogena, H.; Vanderborght, J.; Vrugt, J.A.; Hopmans, J.W. On the value of soil moisture measurements in vadose zone hydrology: A review. Water Resour. Res. 2008, 44, 44. [CrossRef]

3. Tian, J.; Han, Z.B.; Bogena, H.R.; Huisman, J.A.; Montzka, C.; Zhang, B.Q.; He, C.S. Estimation of subsurface soil moisture from surface soil moisture in cold mountainous areas. Hydrol. Earth Syst. Sci. Discuss. 2019, in review. [CrossRef]

4. Koster, R.D.; Dirmeyer, P.A.; Guo, Z.C.; Bonan, G.; Chan, E.; Cox, P.; Gordon, C.T.; Kanae, S.; Kowalczyk, E.; Lawrence, D.; et al. Regions of strong coupling between soil moisture and precipitation. Science 2004, 305, 1138-1140. [CrossRef] [PubMed]

5. Seneviratne, S.I.; Corti, T.; Davin, E.L.; Hirschi, M.; Jaeger, E.B.; Lehner, I.; Orlowsky, B.; Teuling, A.J. Investigating soil moisture-Climate interactions in a changing climate: A review. Earth-Sci. Rev. 2010, 99, 125-161. [CrossRef]

6. Oki, T.; Kanae, S. Global Hydrological Cycles and World Water Resources. Science 2006, 313, $1068-1072$. [CrossRef]

7. Federer, C.A. A Soil-Plant-Atmosphere Model for Transpiration and Availability of Soil Water. Water Resour. Res. 1979, 15, 555-562. [CrossRef] 
8. Zhang, B.Q.; He, C.S.; Burnham, M.; Zhang, L.H. Evaluating the coupling effects of climate aridity and vegetation restoration on soil erosion over the Loess Plateau in China. Sci. Total Environ. 2016, 539, 436-449. [CrossRef]

9. Chen, R.; Kang, E.; Yang, J.; Zhang, J. A distributed daily runoff model of inland river mountainous basin. Adv. Earth Sci. 2003, 18, 198-206. [CrossRef]

10. Zhang, Y.M.; Chen, Y.N.; Pan, B.R. Distribution and floristics of desert plant communities in the lower reaches of Tarim River, southern Xinjiang, People's Republic of China. J. Arid Environ. 2005, 63, 772-784. [CrossRef]

11. Brocca, L.; Tullo, T.; Melone, F.; Moramarco, T.; Morbidelli, R. Catchment scale soil moisture spatial-temporal variability. J. Hydrol. 2012, 422, 63-75. [CrossRef]

12. Robock, A.; Vinnikov, K.Y.; Srinivasan, G.; Entin, J.K.; Hollinger, S.E.; Speranskaya, N.A.; Liu, S.X.; Namkhai, A. The Global Soil Moisture Data Bank. B. Am. Meteorol. Soc. 2000, 81, 1281-1299. [CrossRef]

13. Ochsner, T.E.; Cosh, M.H.; Cuenca, R.H.; Dorigo, W.A.; Draper, C.S.; Hagimoto, Y.; Kerr, Y.H.; Njoku, E.G.; Small, E.E.; Zreda, M. State of the Art in Large-Scale Soil Moisture Monitoring. Soil Sci. Soc. Am. J. 2013, 77, 1888. [CrossRef]

14. Njoku, E.G.; Jackson, T.J.; Lakshmi, V.; Chan, T.K.; Nghiem, S.V. Soil moisture retrieval from AMSR-E. IEEE Trans. Geosci. Remote Sens. 2003, 41, 215-229. [CrossRef]

15. Naeimi, V.; Scipal, K.; Bartalis, Z.; Hasenauer, S.; Wagner, W. An Improved Soil Moisture Retrieval Algorithm for ERS and METOP Scatterometer Observations. IEEE Trans. Geosci. Remote Sens. 2009, 47, 1999-2013. [CrossRef]

16. Wagner, W. Evaluation of the agreement between the first global remotely sensed soil moisture data with model and precipitation data. J. Geophys. Res. Atoms. 2003, 108, 4611. [CrossRef]

17. Wagner, W.; Hahn, S.; Kidd, R.; Melzer, T.; Bartalis, Z.; Hasenauer, S.; Figa-Saldana, J.; de Rosnay, P.; Jann, A.; Schneider, S.; et al. The ASCAT Soil Moisture Product: A Review of its Specifications, Validation Results, and Emerging Applications. Meteorol. Z. 2013, 22, 5-33. [CrossRef]

18. Kerr, Y.H.; Waldteufel, P.; Wigneron, J.-P.; Delwart, S.; Cabot, F.; Boutin, J.; Escorihuela, M.-J.; Font, J.; Reul, N.; Gruhier, C. The SMOS mission: New tool for monitoring key elements ofthe global water cycle. Proc. IEEE 2010, 98, 666-687. [CrossRef]

19. Entekhabi, D.; Njoku, E.G.; O’Neill, P.E.; Kellogg, K.H.; Crow, W.T.; Edelstein, W.N.; Entin, J.K.; Goodman, S.D.; Jackson, T.J.; Johnson, J. The soil moisture active passive (SMAP) mission. Proc. IEEE 2010, 98, 704-716. [CrossRef]

20. Rötzer, K.; Montzka, C.; Vereecken, H. Spatio-temporal variability of global soil moisture products. J. Hydrol. 2015, 522, 187-202. [CrossRef]

21. Xu, C.Y.; Qu, J.J.; Hao, X.J.; Cosh, M.; Prueger, J.; Zhu, Z.L.; Gutenberg, L. Downscaling of Surface Soil Moisture Retrieval by Combining MODIS/Landsat and In Situ Measurements. Remote Sens. 2018, 10, 210. [CrossRef]

22. Zhang, L.H.; He, C.S.; Zhang, M.M. Multi-Scale Evaluation of the SMAP Product Using Sparse In-Situ Network over a High Mountainous Watershed, Northwest China. Remote Sens. 2017, 9, 1111. [CrossRef]

23. Sandholt, I.; Rasmussen, K.; Andersen, J. A simple interpretation of the surface temperature/vegetation index space for assessment of surface moisture status. Remote Sens. Environ. 2002, 79, 213-224. [CrossRef]

24. Watson, K. Geologic applications of thermal infrared images. Proc. IEEE 1975, 63, 128-137. [CrossRef]

25. Price, J.C. On the analysis of thermal infrared imagery: The limited utility of apparent thermal inertia. Remote Sens. Environ. 1985, 18, 59-73. [CrossRef]

26. Li, J.K.; Islam, S. Estimation of root zone soil moisture and surface fluxes partitioning using near surface soil moisture measurements. J. Hydrol. 2002, 259, 1-14. [CrossRef]

27. Tobin, K.J.; Torres, R.; Crow, W.T.; Bennett, M.E. Multi-decadal analysis of root-zone soil moisture applying the exponential filter across CONUS. Hydrol. Earth Syst. Sci. Discuss. 2017, 21, 4403-4417. [CrossRef]

28. Lu, Z.; Chai, L.N.; Liu, S.M.; Cui, H.Z.; Zhang, Y.H.; Jiang, L.M.; Jin, R.; Xu, Z.W. Estimating time series soil moisture by applying recurrent nonlinear autoregressive neural networks to passive microwave data over the Heihe River Basin, China. Remote Sens. 2017, 9, 574. [CrossRef]

29. Mishra, V.; Ellenburg, W.L.; Markert, K.N.; Limaye, A.S. Performance evaluation of soil moisture profile estimation through entropy-based and exponential filter models. Hydrol. Sci. J. 2020, 65, 1036-1048. [CrossRef] 
30. Bablet, A.; Viallefont-Robinet, F.; Jacquemoud, S.; Fabre, S.; Briottet, X. High-resolution mapping of in-depth soil moisture content through a laboratory experiment coupling a spectroradiometer and two hyperspectral cameras. Remote Sens. Environ. 2020, 236, 11. [CrossRef]

31. Parida, B.R.; Oinam, B.; Patel, N.R.; Sharma, N.; Kandwal, R. Land surface temperature variation in relation to vegetation type using MODIS satellite data in Gujarat state of India. Int. J. Remote Sens. 2008, 29, 4219-4235. [CrossRef]

32. Bai, M.; Mo, X.G.; Liu, S.X.; Hu, S. Contributions of climate change and vegetation greening to evapotranspiration trend in a typical hilly-gully basin on the Loess Plateau, China. Sci. Total Environ. 2019, 657, 325-339. [CrossRef] [PubMed]

33. Tucker, C.J. Red and photographic infrared linear combinations for monitoring vegetation. Remote Sens. Environ. 1979, 8, 127-150. [CrossRef]

34. Valor, E.; Caselles, V. Mapping land surface emissivity from NDVI: Application to European, African, and South American areas. Remote Sens. Environ. 1996, 57, 167-184. [CrossRef]

35. Dash, P.; Gottsche, F.M.; Olesen, F.S.; Fischer, H. Land surface temperature and emissivity estimation from passive sensor data: Theory and practice-current trends. Int. J. Remote Sens. 2002, 23, 2563-2594. [CrossRef]

36. Baldwin, D.; Manfreda, S.; Keller, K.; Smithwick, E.A.H. Predicting root zone soil moisture with soil properties and satellite near-surface moisture data across the conterminous United States. J. Hydrol. 2017, 546, 393-404. [CrossRef]

37. Yang, Y.T.; Guan, H.D.; Long, D.; Liu, B.; Qin, G.H.; Qin, J.; Batelaan, O. Estimation of Surface Soil Moisture from Thermal Infrared Remote Sensing Using an Improved Trapezoid Method. Remote Sens. 2015, 7, 8250-8270. [CrossRef]

38. Montzka, C.; Rötzer, K.; Bogena, H.; Sanchez, N.; Vereecken, H. A New Soil Moisture Downscaling Approach for SMAP, SMOS, and ASCAT by Predicting Sub-Grid Variability. Remote Sens. 2018, 10, 427. [CrossRef]

39. Tian, J.; Zhang, B.Q.; He, C.S.; Yang, L.X. Variability in Soil Hydraulic Conductivity and Soil Hydrological Response Under Different Land Covers in the Mountainous Area of the Heihe River Watershed, Northwest China. Land Degrad. Dev. 2017, 28, 1437-1449. [CrossRef]

40. Jin, X.; Zhang, L.H.; Gu, J.; Zhao, C.; Tian, J.; He, C.S. Modelling the impacts of spatial heterogeneity in soil hydraulic properties on hydrological process in the upper reach of the Heihe River in the Qilian Mountains, Northwest China. Hydrol. Process. 2015, 29, 3318-3327. [CrossRef]

41. Ye, Z.; Hong, T.; Chileshe, J.M.; Wen, T.; Feng, R.J. Multi-factor evaluation and modeling correction of EC-5 and 5TE soil moisture content sensors. Trans. Chin. Soc. Agric. Eng. 2012, 28, 157-166. [CrossRef]

42. Tian, J.; Zhang, B.Q.; He, C.S.; Han, Z.B.; Bogena, H.R.; Huisman, J.A. Dynamic response patterns of profile soil moisture wetting events under different land covers in the Mountainous area of the Heihe River Watershed, Northwest China. Agric. For. Meteorol. 2019, 271, 225-239. [CrossRef]

43. Didan, K. MOD13A2 MODIS/Terra Vegetation Indices 16-Day L3 Global 1km SIN Grid V006; LP DAAC: Sioux Falls, SD, USA, 2015. [CrossRef]

44. Wan, Z.; Hook, S.; Hulley, G. MOD11A2 MODIS/Terra Land Surface Temperature/Emissivity 8-Day L3 Global 1km SIN Grid V006; LP DAAC: Sioux Falls, SD, USA, 2015. [CrossRef]

45. Marcal, A.R.S.; Wright, G.G. The use of 'overlapping' NOAA-AVHRR NDVI maximum value composites for Scotland and initial comparisons with the land cover census on a Scottish regional and District basis. Int. J. Remote Sens. 1997, 18, 491-503. [CrossRef]

46. Cihlar, J.; Ly, H.; Li, Z.; Chen, J.M.; Pokrant, H.; Huang, F. Multitemporal, multichannel AVHRR data sets for land biosphere studies-Artifacts and corrections. Remote Sens. Environ. 1997, 60, 35-57. [CrossRef]

47. Kobayashi, H.; Dye, D.G. Atmospheric conditions for monitoring the long-term vegetation dynamics in the Amazon using normalized difference vegetation index. Remote Sens. Environ. 2005, 97, 519-525. [CrossRef] 
48. Jonsson, P.; Eklundh, L. Seasonality extraction by function fitting to time-series of satellite sensor data. IEEE Trans. Geosci. Remote Sens. 2002, 40, 1824-1832. [CrossRef]

49. Beck, P.S.A.; Atzberger, C.; Hogda, K.A.; Johansen, B.; Skidmore, A.K. Improved monitoring of vegetation dynamics at very high latitudes: A new method using MODIS NDVI. Remote Sens. Environ. 2006, 100, 321-334. [CrossRef] 